\title{
Genetic correlations between the cumulative pseudo-survival rate, milk yield, and somatic cell score during lactation in Holstein cattle in Japan using a random regression model
}

\author{
O. Sasaki, ${ }^{* 1}$ M. Aihara, † A. Nishiura, ${ }^{*}$ and H. Takeda* \\ *Institute of Livestock and Grassland Science, National Agriculture and Food Research Organization, Tsukuba 305-0901, Japan \\ †Livestock Improvement Association of Japan Inc., Tokyo 135-0041, Japan
}

\begin{abstract}
Trends in genetic correlations between longevity, milk yield, and somatic cell score (SCS) during lactation in cows are difficult to trace. In this study, changes in the genetic correlations between milk yield, SCS, and cumulative pseudo-survival rate (PSR) during lactation were examined, and the effect of milk yield and SCS information on the reliability of estimated breeding value (EBV) of PSR were determined. Test day milk yield, SCS, and PSR records were obtained for Holstein cows in Japan from 2004 to 2013. A random subset of the data was used for the analysis (825 herds, 205,383 cows). This data set was randomly divided into 5 subsets (162168 herds, 83,389-95,854 cows), and genetic parameters were estimated in each subset independently. Data were analyzed using multiple-trait random regression animal models including either the residual effect for the whole lactation period (H0), the residual effects for 5 lactation stages (H5), or both of these residual effects (HD). Milk yield heritability increased until 310 to $351 \mathrm{~d}$ in milk (DIM) and SCS heritability increased until 330 to 344 DIM. Heritability estimates for PSR increased with DIM from 0.00 to 0.05 . The genetic correlation between milk yield and SCS increased negatively to under -0.60 at 455 DIM. The genetic correlation between milk yield and PSR increased until 342 to 355 DIM (0.53-0.57). The genetic correlation between the SCS and PSR was -0.82 to -0.83 at around 180 DIM, and decreased to -0.65 to -0.71 at 455 DIM. The reliability of EBV of PSR for sires with 30 or more recorded daughters was 0.17 to 0.45 when the effects of correlated traits were ignored. The maximum reliability of EBV was observed at 257 (H0) or 322 (HD) DIM. When the correlations of PSR with milk yield and SCS were considered, the reliabilities of PSR estimates increased to 0.31-0.76. The genetic parameter estimates of $\mathrm{H} 5$ were the same
\end{abstract}

Received November 15, 2016.

Accepted May 23, 2017.

${ }^{1}$ Corresponding author: sasa1@affrc.go.jp as those for HD. The rank correlation coefficients of the EBV of PSR between $\mathrm{H} 0$ and $\mathrm{H} 5$ or $\mathrm{HD}$ were greater than 0.9. Additionally, the reliabilities of EBV of PSR of $\mathrm{H} 0$ were similar to those for $\mathrm{H} 5$ and HD. Therefore, the genetic parameter estimates in $\mathrm{H} 0$ were not substantially different from those in $\mathrm{H} 5$ and HD. When milk yield and SCS, which were genetically correlated with PSR, were used, the reliability of PSR increased. Estimates of the genetic correlations between PSR and milk yield and between PSR and SCS are useful for management and breeding decisions to extend the herd life of cows.

Key words: dairy cattle, genetic evaluation, survivability, reliability

\section{INTRODUCTION}

Estimates of genetic correlations between longevity and milk yield in cows vary among studies (e.g., Tsuruta et al., 2005; Pritchard et al., 2013; Tokuhisa et al., 2014), suggesting variation in environmental factors. Genetic correlations between the length of herd life and milk yield decrease yearly, from high positive values to low negative values (Tsuruta et al., 2004; Hagiya et al., 2012a; Haile-Mariam and Pryce, 2015), indicating that correlations need to be assessed periodically. Negative genetic correlations have been reported between longevity and SCS and between longevity and mastitis (Hagiya et al., 2012b; Pritchard et al., 2013; Weller and Ezra, 2015). In these studies, longevity traits have been estimated for the whole productive life or at each parity. Therefore, trends in genetic correlations between longevity and both milk yield and SCS during lactation could not be traced. The risk of becoming ill for high-producing dairy cows increases as the energy deficit increases in the early stage of lactation (Heuer et al., 1999; Čejna and Chládek, 2005; Toni et al., 2011). Accordingly, the genetic correlation between longevity and milk production may differ among lactation stages; specifically, genetic correlations may be higher during early stages than later lactation stages. Using a random 
regression model, Sasaki et al. (2015) reported that the cumulative pseudo-survival rate (PSR) could reflect changes in genetic parameters during lactation. Therefore, it is possible to assess changes in genetic correlations during lactation between PSR and milk production traits and SCS using random regression models. If these genetic correlations are high, milk production traits and SCS are expected to increase the reliability of the EBV of PSR (Tsuruta et al., 2005; Hagiya et al., 2012b).

In this study, our aim was to investigate changes in genetic correlations among PSR, milk yield, and SCS during lactation and to determine the effect of milk yield and SCS information on the reliability of EBV of PSR. These findings may inform management and breeding decisions aimed at extending the herd life of cows.

\section{MATERIALS AND METHODS}

\section{Data}

Data sets containing test day information from 2004 to 2013 were obtained from the Livestock Improvement Association of Japan (http://liaj.lin.gr.jp/) and from the National Livestock Breeding Center (http://www. nlbc.go.jp/index.asp). The first calving ages of cows in this data set were between 18 and 35 mo. Data from 3,306 herds, containing 110 or more test days from 2008 to 2013 and 25 or more cows per test day, were extracted from this data set and included in the analysis. All data for the first 5 lactation test-day records between 6 and 455 DIM were collected from these herds. The entire data set was randomly divided into 2 subsets based on herds owing to computational limitations, and 1 was used for the analysis. This subset was randomly divided into 5 subsets, using the same criteria as before, and the genetic parameters were estimated in each subset independently (Data1-5; Table 1). The data consisted of test day milk yield, SCS, and PSR records. Test-day SCS was calculated as follows: SCS $=\log _{2}[(\mathrm{SCC}) / 100]$ +3 (Ali and Shook, 1980). The PSR value was esti- mated according to the methods of Sasaki et al. (2015). The day of cow removal from her herd was considered the last test day of the cow when the interval between the last test day of the cow and the last test day of her herd was longer than $120 \mathrm{~d}$. When the interval between the last test day of the cow and the last test day of her herd was less than $120 \mathrm{~d}$, the last test day of the cow was considered the day of censoring. When a cow was alive until September 2013, or when her herd was withdrawn from the herd test, the cow had a censored record. The calving records of a cow that was removed before the first test day of lactation were not included in the data set. The removal day of this cow was the dry-off day of prior parity. The PSR value was determined according to whether the cow was alive (1) or absent (0) in her herd on the test day within the lactation period. The PSR record for the last test day before the removal day of a cow was coded 0 , and the subsequent test-day records in the same parity for the cow were coded 0 until 455 DIM. The PSR record of a cow in the parities before the parity at removal was coded 1, and the last test day before the dry-off day of a cow was considered the day of censoring. The PSR record for the day of censoring of a cow was coded as 1 , and the subsequent test-day records in the same parity of the cow were considered missing. When a cow was dried off after 455 DIM, the last test day of the cow before 456 DIM was considered the day of censoring and it was coded 1 . When a cow was removed after 455 DIM, the last test day of the cow before 456 DIM was considered the removal day, and it was coded 0 . The PSR records in the parities subsequent to the removal parity were considered missing. Related animals in the pedigree record were defined as cows for which PSR records were available and the ancestors traced back 3 generations from the cows with test-day records (Table $1)$.

\section{Models}

Data were analyzed using the multiple-trait random regression animal model, with slightly different models

Table 1. Summary of raw data used to estimate genetic parameters for each data set (Data1-5)

\begin{tabular}{|c|c|c|c|c|c|c|c|c|c|c|}
\hline Data set & $\begin{array}{l}\text { No. of } \\
\text { herds }\end{array}$ & $\begin{array}{c}\text { No. of } \\
\text { cows }\end{array}$ & $\begin{array}{l}\text { No. of } \\
\text { related } \\
\text { animals }\end{array}$ & $\begin{array}{l}\text { No. of } \\
\text { cows } \\
\text { removed }\end{array}$ & \multicolumn{3}{|c|}{ Milk yield } & \multicolumn{3}{|c|}{ SCS } \\
\hline Data2 & 168 & 42,025 & 93,805 & 25,633 & $1,042,383$ & 29.8 & 9.0 & $1,037,861$ & 2.62 & 1.82 \\
\hline Data3 & 162 & 40,888 & 83,389 & 24,386 & $1,044,649$ & 29.5 & 9.0 & $1,038,200$ & 2.67 & 1.86 \\
\hline Data4 & 164 & 40,361 & 85,252 & 24,517 & $1,007,869$ & 28.8 & 8.9 & $1,006,702$ & 2.65 & 1.84 \\
\hline
\end{tabular}


for milk and SCS than for PSR. The following model was used for daily milk yield and SCS:

$$
\begin{aligned}
y_{\text {dijklmt }}= & \mathrm{HTD}_{i t}+\sum_{s=0}^{6} \operatorname{RPA}_{j t s} \varphi_{s}(d)+\sum_{s=0}^{2} \operatorname{HYS}_{k t s} \varphi_{s}(d) \\
& +\sum_{s=0}^{2} \mathrm{a}_{l t s} \varphi_{s}(d)+\sum_{s=0}^{2} \mathrm{p1}_{l t s} \varphi_{s}(d)+\sum_{s=0}^{2} \mathrm{p} 2_{l m t s} \varphi_{s}(d) \\
& +\mathrm{e} 1_{w d i j k l m t}+\mathrm{e} 2_{d i j k l m t} .
\end{aligned}
$$

The following model was used for PSR:

$$
\begin{aligned}
y_{d j k l m} & =\sum_{s=0}^{4} \operatorname{RPA}_{j s} \varphi_{s}(d)+\sum_{s=0}^{2} \mathrm{HYS}_{k s} \varphi_{s}(d)+\sum_{\mathrm{s}=0}^{2} \mathrm{a}_{l s} \varphi_{s}(d) \\
& +\sum_{s=0}^{2} \mathrm{p}_{l m s} \varphi_{s}(d)+\mathrm{e} 1_{w d j k l m}+\mathrm{e} 2_{d j k l m}
\end{aligned}
$$

where $y_{d i j k l m t}$ is the milk yield and SCS and $y_{d j k l m}$ is the PSR of cow $l$ exhibiting trait $t$ at DIM $d$. HTD $i t$ is the fixed effect of the herd-test day $i$ with trait $t . \mathrm{RPA}_{j t s}$ is the sth fixed regression coefficient of the region-parityage of calving group $j$ with trait $t$. RPA $j$ is the sth fixed regression coefficient of the region-parity-age of calving group $j$ for PSR. The region classes were Hokkaido and other regions in Japan. The age groups at calving were divided into 5 classes in each parity. $\mathrm{HYS}_{k t s}$ is the sth random regression coefficient of the herd-year-season group $k$ with trait $t$. $\mathrm{HYS}_{k s}$ is the $s$ th fixed regression coefficient of the herd-year-season group $k$ for PSR. The season was divided into 4 classes: from January to March, April to June, July to September, and October to December. $\mathrm{a}_{l t s}$ represents the sth additive genetic random regression coefficient of cow $l$ exhibiting trait $t$. $\mathrm{a}_{l s}$ represents the $s$ th additive genetic random regression coefficient of cow $l$ for PSR. p1 $1_{l t s}$ represents the $s$ th permanent environmental random regression coefficient of cow $l$ between lactation with trait $t$. $\mathrm{p} 2_{l m t s}$ represents the sth permanent environmental random regression coefficient of cow $l$ within lactation $m$ with trait $t(m=$ 1-5). $\mathrm{p} 2_{l m s}$ represents the sth permanent environmental random regression coefficient of cow $l$ within lactation $\mathrm{m}$ for PSR. $\mathrm{e} 1_{\text {wdijklmt }}$ represents the residual random effect of lactation stage $w$ with trait $t$. e $1_{w d j k l m}$ represents the residual random effect of lactation stage $w$ for PSR. Five groups were established according to lactation stage: from 6 to 95,96 to 185,186 to 275,276 to 365 , and 366 to 455 DIM. e2 $2_{d i j k l m t}$ represents the residual random effect for the whole lactation. $\mathrm{e} 2_{d j k l m}$ represents the residual random effect for the whole lactation for
PSR. $\varphi_{s}(d)$ is the sth Legendre polynomial at DIM $d$. The variance and covariance were defined as follows:

$$
\operatorname{var}\left[\begin{array}{c}
\mathbf{a} \\
\mathbf{p} 1 \\
\mathbf{p} 2 \\
\mathbf{e} 1_{w} \\
\mathbf{e} 2
\end{array}\right]=\left[\begin{array}{ccccc}
\mathbf{G} \otimes \mathbf{A} & 0 & 0 & 0 & 0 \\
0 & \mathbf{Q} 1 \otimes \mathbf{I} & 0 & 0 & 0 \\
0 & 0 & \mathbf{Q} 2 \otimes \mathbf{I} & 0 & 0 \\
0 & 0 & 0 & \mathbf{R} 1_{\boldsymbol{w}} \otimes \mathbf{I} & 0 \\
0 & 0 & 0 & 0 & \mathbf{R} 2 \otimes \mathbf{I}
\end{array}\right]
$$

where $\mathbf{a}, \mathbf{p} \mathbf{1}$, and $\mathbf{p} \mathbf{2}$ are vectors of the regression coefficients for the additive genetic effect, permanent environmental effect between lactation, and permanent environmental effect within lactation, respectively. The dimensions of $\mathbf{a}, \mathbf{p} \mathbf{1}$, and $\mathbf{p} \mathbf{2}$ for milk yield and SCS were the same as those in the model for routine evaluation work in Japan. The dimensions of $\mathbf{a}$ and $\mathbf{p} \mathbf{2}$ of PSR were the same as those used in the model in Sasaki et al. (2015). $\mathbf{e} \mathbf{1}_{w}$ is a vector of the residual effect of lactation stage group $w$. $\mathbf{e} 2$ is a vector of the residual effect of the whole lactation period. G, Q1, and Q2 are the (co)variance matrices for the additive genetic, permanent environmental between lactation, and permanent environmental within lactation regression coefficients, respectively. $\mathbf{R} 1_{w}$ is the residual (co)variance matrix of the lactation stage group $w$. $\mathbf{R} 2$ is the residual (co) variance matrix of the whole lactation period. The covariance elements between the lactation stage groups of $\mathbf{R} \mathbf{1}_{w}$ were set to zero because the test day observations for each trait were only included in 1 lactation stage group. $\mathbf{A}$ is the additive genetic relationship matrix between animals. $\mathbf{I}$ is the identity matrix.

\section{Heterogeneity of Residual Variances}

Three models were used to evaluate the heterogeneity of residual variances (RV) in Equations [1] and [2]. The first model (Ho) included the e2 effect and ignored the e1 effect. The second model (H5) included the e1 effect and ignored the e 2 effect. The third model (HD) included the e1 and e2 effects. These models were compared based on RV (Bohmanova et al., 2009), which were estimated as follows:

$$
\mathrm{RV}=\frac{\sum_{i=1}^{m}\left(y_{i}-\hat{y}_{i}\right)^{2}-\frac{\left[\sum_{i=1}^{m}\left(y_{i}-\hat{y}_{i}\right)\right]^{2}}{m}}{m-1},
$$

where $y_{i}$ is the $i$ th test day record, $\hat{y}_{i}$ is the estimate of the $i$ th test day record, and $m$ is the number of records. 


\section{Parameter Estimates}

The variances in Data1-5 were estimated separately using GIBBS3F90 (Misztal et al., 2002). The first 100,000 Gibbs samples were discarded as the burn-in. Convergence was checked by visually inspecting the graph of the next 100,000 samples, which were used to calculate the posterior means for (co)variance components and heritabilities at test d 6 to 455 DIM. PostGibbs analysis was performed using POSTGIBBSF90 (Tsuruta and Misztal, 2006). When $\boldsymbol{\Phi}_{\boldsymbol{d}}^{\prime}=\left[\begin{array}{lll}\varphi_{0}(d) & \varphi_{1}(d) & \varphi_{2}(d)\end{array}\right]^{\prime}$, the matrices for daily additive genetic (co)variance $\left(\hat{\mathbf{G}}_{\boldsymbol{d}}\right)$, permanent environmental (co)variance between lactation $\left(\widehat{\mathbf{Q}}_{\boldsymbol{d}}\right)$, and permanent environmental (co)variance within lactation $\left(\widehat{\mathrm{Q} 2}_{\boldsymbol{d}}\right)$ at $d$ DIM were defined as $\hat{\mathrm{G}}_{\boldsymbol{d}}=\boldsymbol{\Phi}_{\boldsymbol{d}}^{\prime} \hat{\mathrm{G}} \boldsymbol{\Phi}_{\boldsymbol{d}}$, $\widehat{\mathrm{Q} 1}_{d}=\boldsymbol{\Phi}_{d}^{\prime} \widehat{\mathrm{Q} 1} \Phi_{d}$, and $\widehat{\mathrm{Q} 2}_{d}=\boldsymbol{\Phi}_{d}^{\prime} \widehat{\mathrm{Q} 2} \Phi_{d}$, respectively. Heritability at $d \operatorname{DIM}\left(\hat{\mathrm{h}}_{d}^{2}\right)$ was defined as follows:

$$
\hat{\mathrm{h}}_{d}^{2}=\frac{\hat{\sigma}_{\mathrm{g}_{d}}^{2}}{\hat{\sigma}_{\mathrm{g}_{d}}^{2}+\hat{\sigma}_{\mathrm{p}_{d}}^{2}+\hat{\sigma}_{\mathrm{p}_{d}}^{2}+\hat{\sigma}_{\mathrm{r} 1_{d}}^{2}+\hat{\sigma}_{\mathrm{r} 2_{d}}^{2}},
$$

where $\hat{\sigma}_{\mathrm{g}_{d}}^{2}, \hat{\sigma}_{\mathrm{p}_{d}}^{2}, \hat{\sigma}_{\mathrm{p}_{d} 2_{d}}^{2}, \hat{\sigma}_{\mathrm{r}_{d}}^{2}$, and $\hat{\sigma}_{\mathrm{r}_{d}}^{2}$ are the additive genetic variance, permanent environmental variance between lactation, permanent environmental variance within lactation, RV of the corresponding lactation stage group, and RV of the whole lactation period at $d$ DIM, respectively. The daily genetic correlations between trait 1 and trait 2 at $d \operatorname{DIM}\left(\hat{\mathrm{r}}_{\mathrm{g}_{1 \mathrm{~g} 2_{d}}}\right)$ were estimated according to Equation [6].

$$
\hat{\mathrm{r}}_{\mathrm{g} 1 \mathrm{~g} 2_{d}}=\frac{\widehat{\operatorname{Cov}}_{\mathrm{g} 1 \mathrm{~g} 2_{d}}}{\sqrt{\hat{\mathrm{\sigma}}_{\mathrm{g} 1_{d}}^{2} \times \hat{\sigma}_{\mathrm{g} 2_{d}}^{2}}},
$$

where $\widehat{\operatorname{Cov}}_{g_{1 g} 2}$ is the genetic covariance between trait 1 and trait 2 at $d$ DIM. $\hat{\sigma}_{\mathrm{g}_{d}}^{2}$ and $\hat{\sigma}_{\mathrm{g} 2_{d}}^{2}$ are the genetic variances of trait 1 and 2 at $d$ DIM, respectively.

\section{EBV and Reliability of PSR}

The EBV of PSR at 305 DIM was predicted for Data1-5 using GIBBS3F90 (Misztal et al., 2002). These analyses were performed using the genetic parameter estimates for each data set.

The EBV of PSR obtained by linear model was compared with the EBV of the relative risk (RR) of the Weibull proportional hazard model (PHM) to confirm whether the EBV of PSR reflects longevity. The ETA of the RR of PHM was estimated using The Survival
Kit version 6.1 (Ducrocq et al., 2010). This analysis was performed using the analytical model and parameters reported in Sasaki et al. (2015). The model for PHM was as follows:

$$
\lambda(\delta)=\lambda_{0, p}(\delta) \exp \left[\operatorname{RPA}_{i}+\operatorname{hys}_{j}\left(\delta^{\prime}\right)+\operatorname{sire}_{k}+0.5 \mathrm{mgs}_{l}\right],
$$

where $\lambda(\delta)$ is a hazard function of a cow at $d$ DIM $(\delta=$ $d-5) . \lambda_{0, p}(\delta)=\lambda_{p} \rho_{p}\left(\lambda_{p} \delta\right)^{\rho_{p}}$ is the Weibull baseline hazard function featuring the scale parameter $\lambda_{p}$ and the shape parameter $\rho_{p}$ specific to the region-paritylactation stage group $p$. The lactation stage was divided into 2 classes: from 6 to 255 DIM and from 266 to 455 DIM. $\mathrm{RPA}_{i}$ is the fixed effect of region-parity-age for calving group $i$. hys ${ }_{j}(\delta)$ is the time-dependent random effect of herd-year-season group $j$ at date $\delta^{\prime}$; this effect is assumed to follow a log-gamma distribution $\left(\gamma_{\text {hys }}\right)$ where $\sigma_{\text {hys }}^{2}=\Psi^{(1)}\left(\gamma_{\text {hys }}\right)$, and $\Psi^{(1)}\left(\gamma_{\text {hys }}\right)$ is a trigamma function of $\gamma_{\text {hys }}$. sire ${ }_{k}+0.5 \mathrm{mgs}_{l}$ is the additive genetic effect of the cow's sire and maternal grandsire, which follows a multivariate normal distribution with mean zero and variance $\mathbf{A} \sigma_{\mathrm{s}}^{2}$, where $\sigma_{\mathrm{s}}^{2}$ is the variance among sires and $\mathbf{A}$ is the additive genetic relationship matrix between sires. Twice the ETA of the RR was considered the EBV of the RR.

The EBV of PSR at 305 DIM and the EBV of RR for sires with 30 or more recorded daughters (Sire30) in Data1-5 were selected. The EBV of RR for these same sires were selected in each data set. The Spearman's correlation coefficients for all pairs of EBV were calculated using the CORR procedures of SAS (SAS Institute Inc., 2006).

In Data1, the reliabilities of the EBV of daily PSR of Sire30 were estimated using the method of Liu et al. $(2001,2004)$. This reliability approximation method is based on the concept of the multiple-trait effective daughter contribution for the random regression model. The reliabilities of the EBV were estimated in 4 cases (i.e., using PSR information; PSR and milk yield; PSR and SCS; and PSR, milk yield, and SCS).

\section{RESULTS AND DISCUSSION}

\section{Parameter Estimates}

The additive genetic variance, the permanent environmental variance among parities, and the permanent environmental variance within parities for milk yield increased rapidly after 300 DIM (Figure 1a, 1b, 1c). Because the data points decreased from 3000 to 400 during the period from 250 to 455 DIM, the variance 
in regression estimates is expected to increase. The additive genetic variance and permanent environmental variance among parities for milk yield in $\mathrm{H} 0$ were slightly smaller than those in $\mathrm{H} 5$ and HD. The permanent environmental variance within parities for milk yield was larger than other variance components of milk yield. The permanent environmental variance within parities of milk yield in $\mathrm{H} 0$ was larger than the variances in $\mathrm{H} 5$ and HD until 301 DIM, after which those in $\mathrm{H} 5$ and $\mathrm{HD}$ were larger. In the first lactation stage group, the RV of milk yield in $\mathrm{H} 5$ and HD were larger than that in H0 (Figure 1d). The magnitude of the RV of milk yield in $\mathrm{H} 0$ overtook those in $\mathrm{H} 5$ and HD after the first lactation stage. The heritability estimates of milk yield increased with DIM and peaks were observed at 351 DIM in $\mathrm{H} 0$ and 310 to 311 DIM in H5 and HD (Figure 1e). The heritability of milk yield in $\mathrm{H} 0$ was lower than the milk yield heritability in H5 and HD until 402 DIM. The heritability estimates of milk yield were within the range of previous estimates (Muir et al., 2007; Savegnago et al., 2013; Hagiya et al., 2013, 2014). The additive genetic variance (Figure 2a) and the permanent environmental variance among parities of SCS (Figure 2b) peaked at 235 and 205 DIM, respectively. The additive genetic variance of SCS in H0 was smaller than that in $\mathrm{H} 5$ and $\mathrm{HD}$ in the late lactation stage. In the middle lactation stage, the permanent environmental variance among parities of SCS in $\mathrm{H} 0$ was larger than that in $\mathrm{H} 5$ and HD. The permanent environmental variance within parities was larger than the other variance components of SCS (Figure 2c). This variance was large in the early and late lactation stages. This variance in $\mathrm{H} 0$ was larger in the early lactation stage than the variance in $\mathrm{H} 5$ and $\mathrm{HD}$, but the variances in $\mathrm{H} 5$ and $\mathrm{HD}$ exceeded that of $\mathrm{H} 0$ in the late lactation stage. The RV of SCS in H5 and HD decreased as the lactation stage increased (Figure 2d). These variances in $\mathrm{H} 5$ and $\mathrm{HD}$ were smaller than that in $\mathrm{H} 0$ after the second lactation stage. The heritability of SCS increased until 330 to 344 DIM, and then decreased (Figure 2e). The heritability estimates of SCS in $\mathrm{H} 5$ and $\mathrm{HD}$ were almost the same. The heritability of SCS in $\mathrm{H} 0$ was smaller than those in $\mathrm{H} 5$ and HD after the second lactation stage. The heritability estimates of SCS were within the range of previous estimates (Mrode et al., 2012; Yamazaki et al., 2013; Hagiya et al., 2014).

The additive genetic variance (Figure 3a) and the permanent environmental variance within parities (Figure 3b) of PSR increased with advancing lactation stages. These variances in $\mathrm{H} 0$ were smaller than those in H5 and HD until 371 and 380 DIM, respectively. The RV of PSR in H5 and HD increased as lactation advanced (Figure 3c). These were larger than that in
H0 after the third lactation stage. The heritability of PSR in H0 increased with advancing lactation stages until 396 DIM (Figure 3d). The trends in heritability estimates of PSR in H5 and HD during lactation were similar to those in H0, but heritability was lower in the fifth lactation stage than in H0 (Figure 3e). The trend in the heritability of PSR during lactation in this study was the same as that reported by Sasaki et al. (2015), who used data from 2001 to 2010 . The heritability of PSR was slightly lower than that of the previous study, and this difference might reflect differences in herd size. A herd in the previous study included 5 or more thirdlactation cows on every test-day; different lactations were treated as correlated traits in the multiple-trait model. The average herd size of 70.9 in the previous study was larger than that of this study (i.e., 54.4). Therefore, the differences in results among studies reflect differences in the conditions of herds. Longevity is expressed by various traits, including herd life, life span score, mortality, and so on. The heritability estimates of these longevity traits in previous reports are low (0.04-0.11: Pritchard et al., 2013; Tokuhisa et al., 2014; Weller and Ezra, 2015).

\section{Genetic Correlations}

Small, negative genetic correlations between milk yield and SCS were detected after parturition, and they became more negative as the lactation stage increased (Figure $4 \mathrm{a}$ ). The values were below -0.6 at 455 DIM. The genetic correlations between milk yield and SCS in H0, H5, and HD were very similar. A small, positive genetic correlation between milk yield and SCS has been observed in the first parity, and negative correlations have been observed thereafter (Miglior et al., 2007; Yamazaki et al., 2013). In these reports, the genetic correlation between milk yield and SCS in the late lactation stage ranged from -0.4 to -0.5 . The genetic correlation between milk yield and SCS in this study using the first 5 lactation records agrees with the results obtained for multiparous cows. The genetic correlations between milk yield and PSR increased until 342 to 355 DIM (Figure 4b). This genetic correlation in $\mathrm{H} 0$ was stronger than those in $\mathrm{H} 5$ and $\mathrm{HD}$ from the third lactation stage. The SCS and PSR showed a genetically strong negative relationship (Figure 4c). The peak genetic correlation coefficients ranged from -0.82 to -0.83 around 180 DIM. After 180 DIM, the correlations observed in $\mathrm{H} 0, \mathrm{H} 5$, and HD decreased to $-0.65,-0.71$, and -0.69 at 455 DIM, respectively. The genetic correlation between longevity and milk yield varies among studies. Previous studies have reported that the genetic correlation between longevity and milk yield is positive (Haile-Mariam et al., 2003; Holtsmark 
(a) Additive genetic

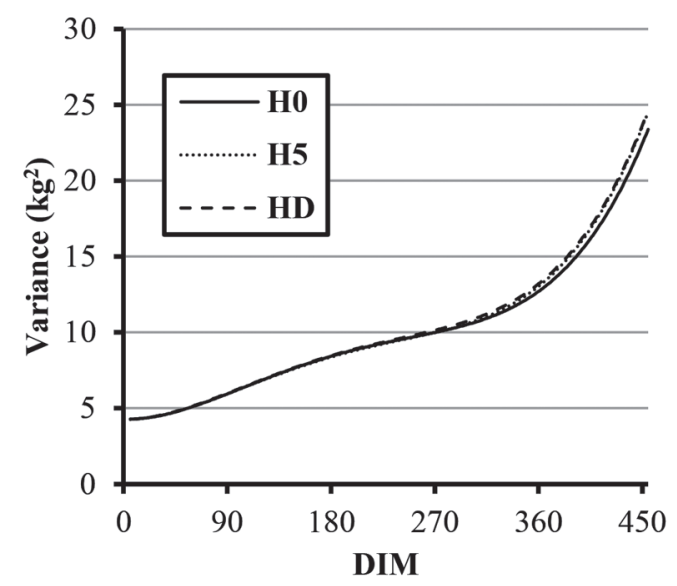

(c) Permanent environmental within lactation

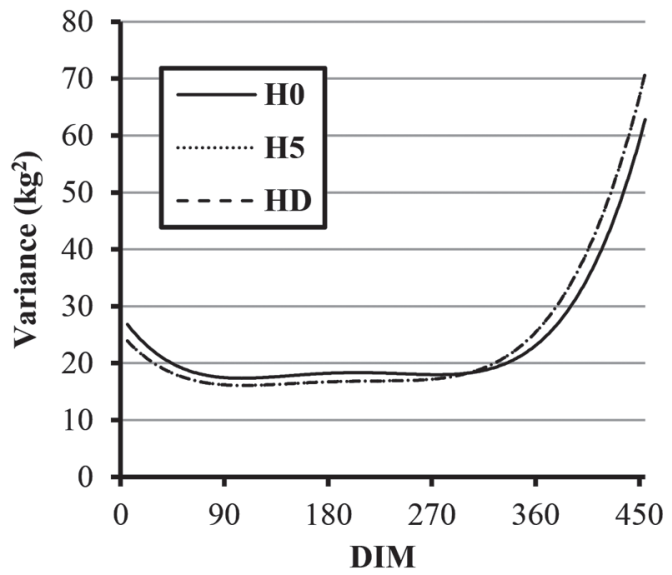

(e) Heritability

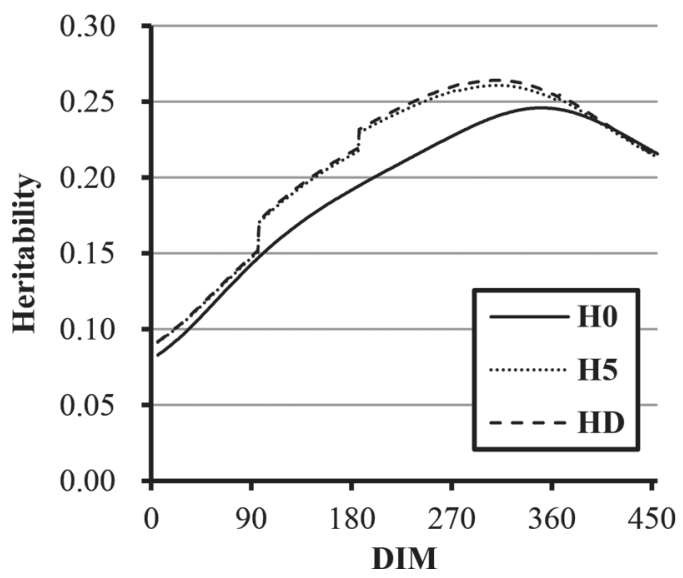

(b) Permanent environmental between lactation

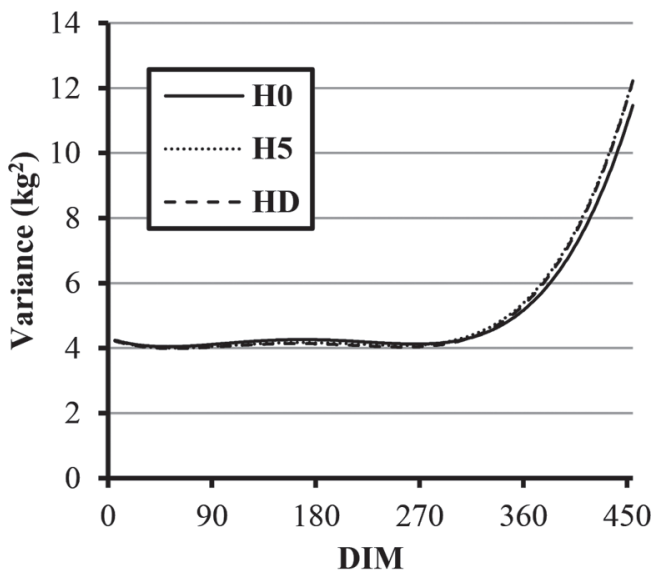

(d) Residual

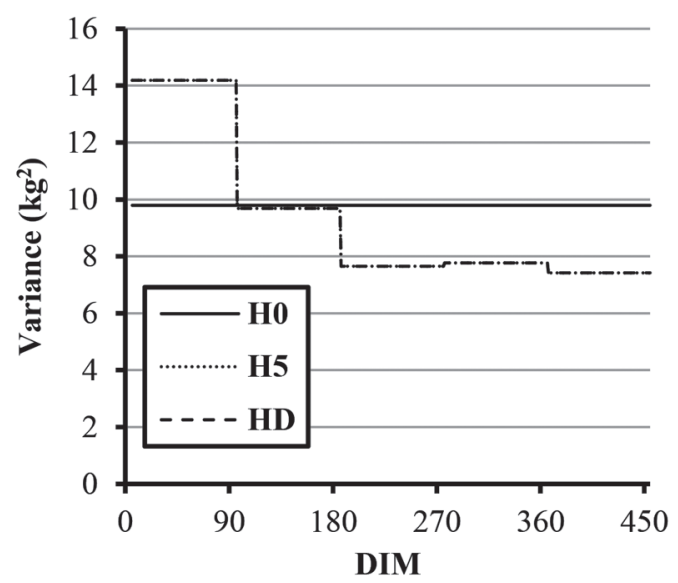

Figure 1. Genetic parameter estimates of the milk yield for each residual variance type (H0 = 1 residual variance for the whole lactation stage; $\mathrm{H} 5=$ separate residual variances for 5 lactation stages; $\mathrm{HD}=1$ residual variance for whole lactation stage + separate residual variances for 5 lactation stages). (a) Estimated additive genetic variance, (b) estimated permanent environmental variance between lactation, (c) estimated permanent environmental variance within lactation, (d) estimated residual variance, (e) estimated heritability. 
(a) Additive genetic

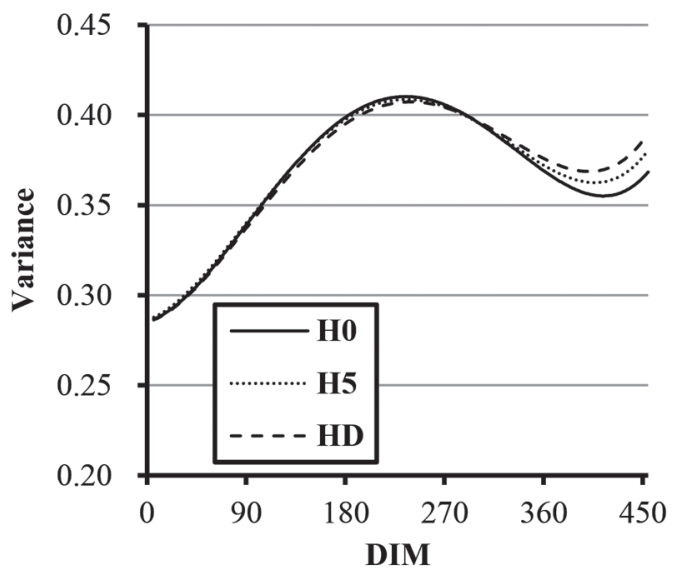

(c) Permanent environmental within lactation

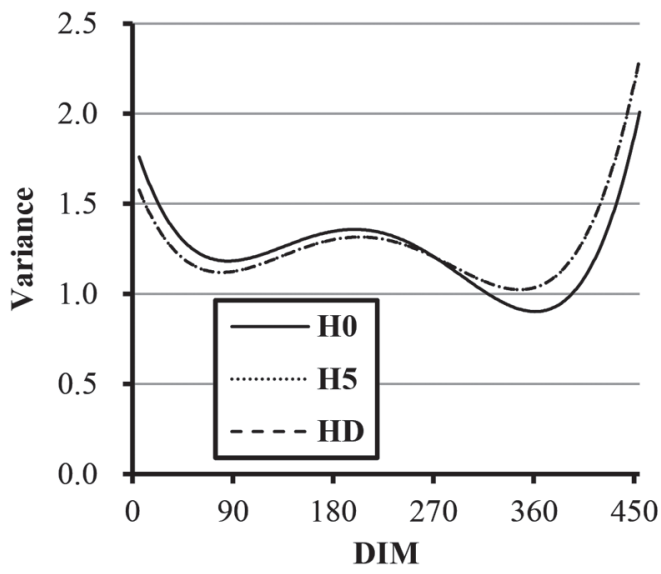

(e) Heritability

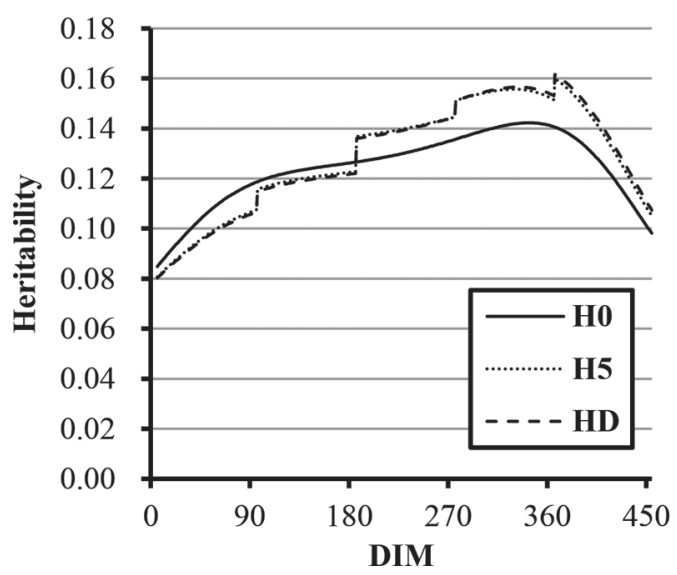

(b) Permanent environmental between lactation

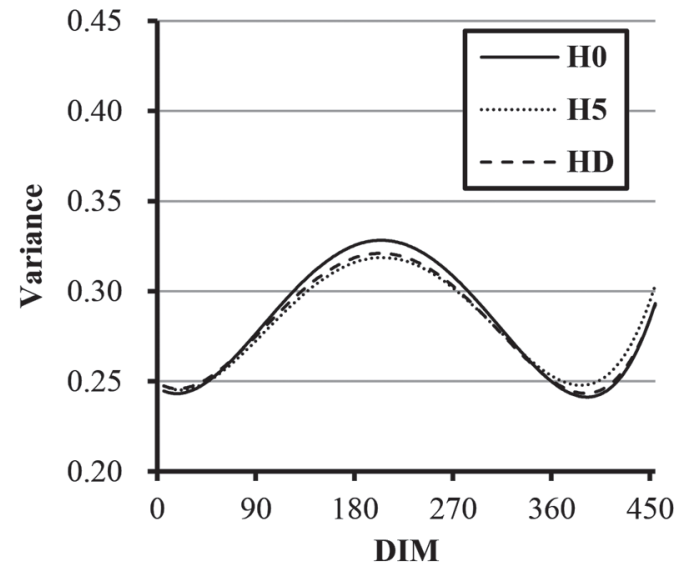

(d) Residual

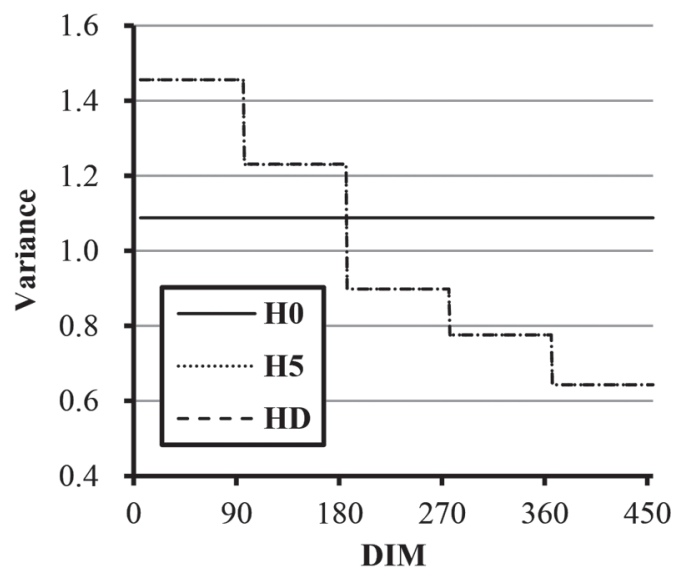

Figure 2. Genetic parameter estimates of the SCS for each residual variance type (H0 = 1 residual variance for the whole lactation stage; H5 $=$ separate residual variances for 5 lactation stages; $\mathrm{HD}=1$ residual variance for the whole lactation stage + separate residual variances for the 5 lactation stages). (a) Estimated additive genetic variance, (b) estimated permanent environmental variance between lactation, (c) estimated permanent environmental variance within lactation, (d) estimated residual variance, (e) estimated heritability. 
(a) Additive genetic

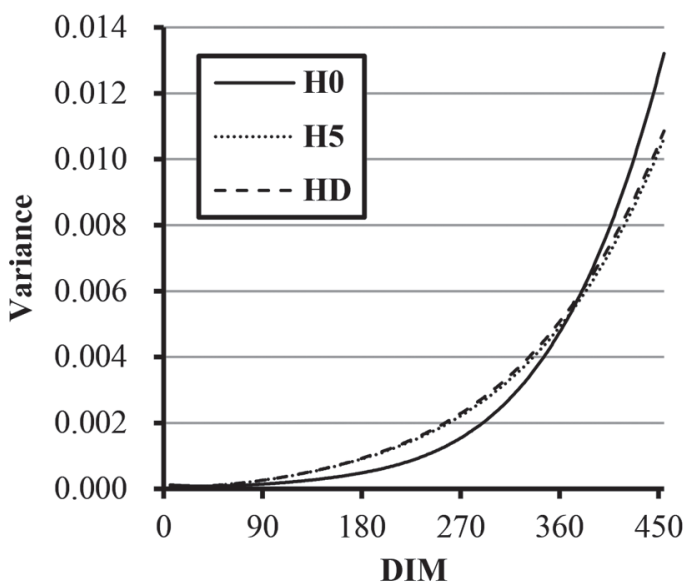

(c) Residual

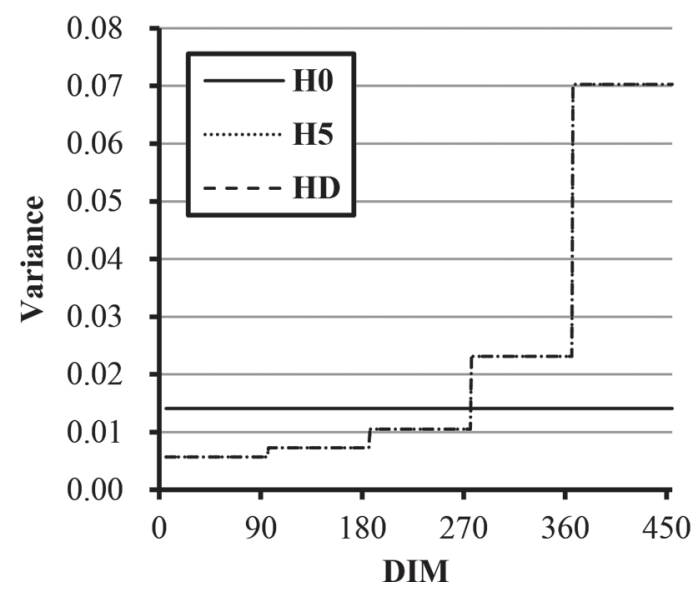

(b) Permanent environmental within lactation

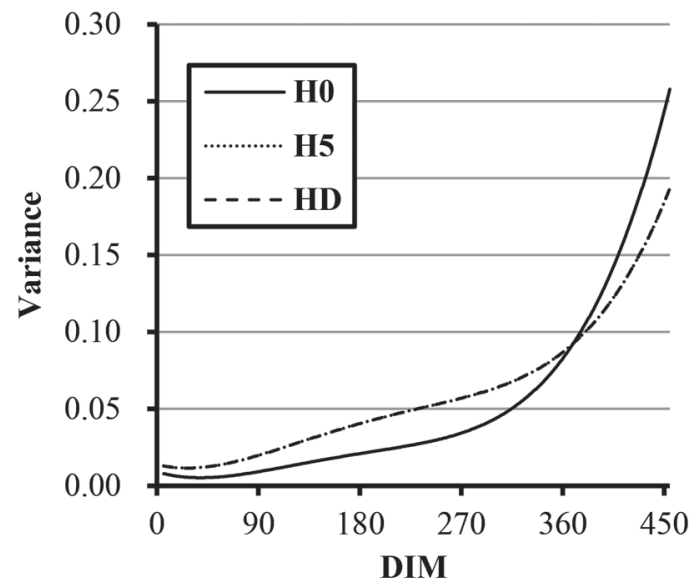

(d) Heritability

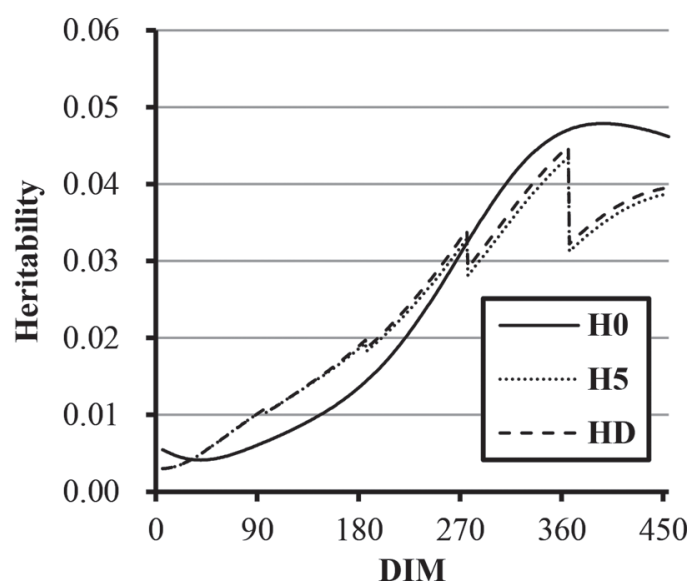

Figure 3. Genetic parameter estimates of the cumulative pseudo-survival rate for each residual variance type (H0 $=1$ residual variance for the whole lactation stage; $\mathrm{H} 5=$ separate residual variances for the 5 lactation stages; HD $=1$ residual variance for the whole lactation stage + separate residual variances for the 5 lactation stages). (a) Estimated additive genetic variance, (b) estimated permanent environmental variance within lactation, (c) estimated residual variance, (d) estimated heritability.

et al., 2008; Pritchard et al., 2013), negative (GonzálezRecio and Alenda, 2007; Onyiro et al., 2008; Tokuhisa et al., 2014), or weak (Tsuruta et al., 2005; Fujita and Suzuki, 2006; Hagiya et al., 2012b). These differences suggest that the genetic correlation between longevity traits and milk yield is dependent on the conditions of individual populations. Hagiya et al. (2012b) reported that the milk yield in the first lactation is not genetically correlated with the length of herd life. However, the genetic correlation of the milk yield between the first lactation and later lactations was not strong (0.76-0.85: Miglior et al., 2007; Yamazaki et al., 2013). Therefore, the milk yield in later lactations may be genetically correlated with longevity traits. Tokuhisa et al. (2014) reported that the genetic correlation between the milk yield and dairy cow mortality differed with respect to parity and region in the United States. Many previous reports have indicated that the culling risk of cows with high SCS records is high (Hagiya et al., 2012b; Pritchard et al., 2013; Weller and Ezra, 2015), in agreement with the results of this study.

\section{Comparisons of Models}

The genetic parameter estimates in H5 were the same as those in HD. This result indicated that the error variance separation methods used in this study did not affect the genetic parameter estimates. The error variance estimates in $\mathrm{H} 0$ were different from those in $\mathrm{H} 5$ and HD, but the heritability estimates and the genetic correlation estimates in $\mathrm{H} 0$ were similar to those in $\mathrm{H} 5$ and HD. The differences in the error variance estimates 
between $\mathrm{H} 0$ and $\mathrm{H} 5$ or $\mathrm{HD}$ are covered by the difference in the permanent environmental variance within parity. Therefore, part of the error variance during lactation in $\mathrm{H} 0$ would be explained by the variance in the permanent environmental effect within lactation. The heritability estimates in the late lactation stage of $\mathrm{H} 0$ were higher than those in $\mathrm{H} 5$ and HD. These results indicated that the error variance estimates in the late lactation stage of $\mathrm{H} 0$ may be underestimated. Almost all effective sample sizes of the variance estimates were over 10 , but the RV estimates in HD were small (2.6 to 34.8$)$. These results are common for complex models (Varona et al., 1999). The variance estimates for the 3 models considered in this study were reliable and not substantially different among the 5 data sets. However, the variance estimates for HD should be verified using another model or multiple data sets. The RV for milk yield and SCS in H0 was smaller than those in
H5 and HD (Table 2). The RV of milk yield and SCS in H5 was almost the same as that in HD. The RV of PSR was similar for all 3 models. In Data1-5, the time required to estimate the $\mathrm{EBV}$ in $\mathrm{H} 0$ was $70 \%$ of the time required in $\mathrm{H} 5$ and $65 \%$ of that for $\mathrm{HD}$, indicating an advantage of $\mathrm{H} 0$ over $\mathrm{H} 5$ and $\mathrm{HD}$ with respect to estimation time.

\section{Reliability of EBV}

Carlén et al. (2006) reported that the correlation coefficients for the comparison between the true breeding value and the predicted breeding value from a linear model, threshold model, and survival analysis were similar. Additionally, they reported that the accuracy of the ranking of sires by predicted breeding value was similar for these 3 models. In this study, the results obtained using the linear model were compared with (a) Milk and SCS

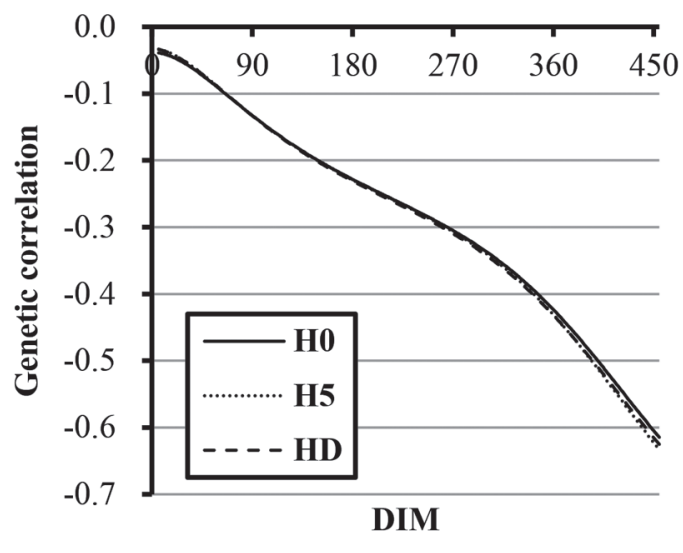

(c) SCS and PSR

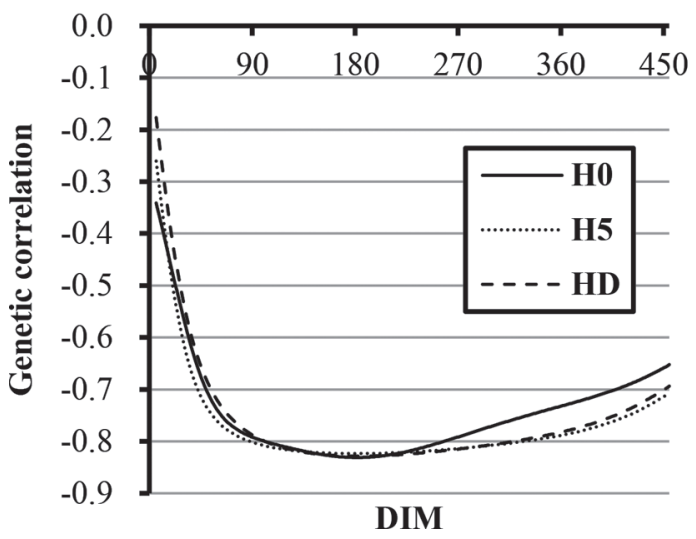

(b) Milk and PSR

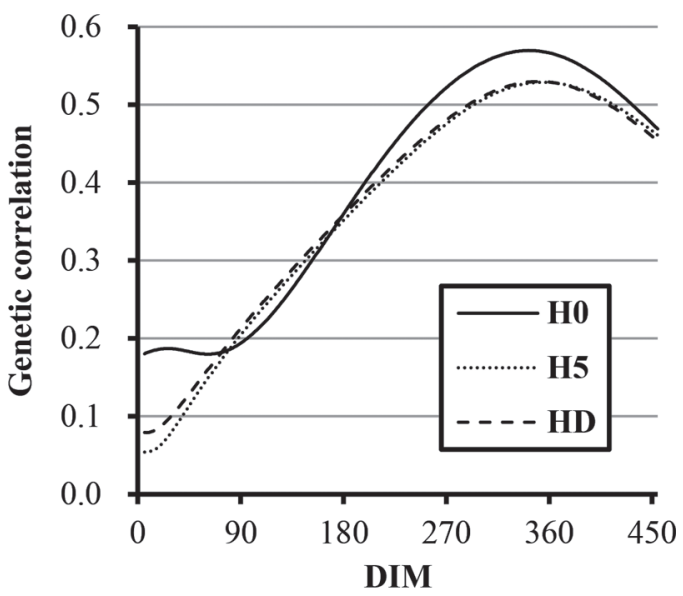


Table 2. Residual variance for various models and each residual variance type $(\mathrm{H} 0=1$ residual variance for the whole lactation stage; $\mathrm{H} 5=$ separate residual variances for 5 lactation stages; $\mathrm{HD}=1$ residual variance for the whole lactation stage + separate residual variances for 5 lactation stages) for each data set (Data1-5)

\begin{tabular}{|c|c|c|c|c|c|c|c|c|c|}
\hline \multirow[b]{2}{*}{ Data set } & \multicolumn{3}{|c|}{ Milk } & \multicolumn{3}{|c|}{ SCS } & \multicolumn{3}{|c|}{$\mathrm{PSR}^{1}$} \\
\hline & Ho & H5 & HD & Ho & H5 & HD & Ho & H5 & HD \\
\hline Data1 & 7.55 & 7.67 & 7.67 & 0.873 & 0.883 & 0.884 & 0.0112 & 0.0114 & 0.0114 \\
\hline Data2 & 7.44 & 7.56 & 7.56 & 0.843 & 0.853 & 0.853 & 0.0115 & 0.0117 & 0.0117 \\
\hline Data3 & 7.42 & 7.54 & 7.54 & 0.860 & 0.871 & 0.871 & 0.0115 & 0.0110 & 0.0110 \\
\hline Data4 & 7.36 & 7.47 & 7.47 & 0.840 & 0.850 & 0.850 & 0.0116 & 0.0118 & 0.0118 \\
\hline Data5 & 7.98 & 8.11 & 8.11 & 0.826 & 0.836 & 0.836 & 0.0116 & 0.0117 & 0.0117 \\
\hline Average & 7.55 & 7.67 & 7.67 & 0.848 & 0.858 & 0.859 & 0.0115 & 0.0115 & 0.0115 \\
\hline
\end{tabular}

${ }^{1}$ Pseudo-survival rate.

those obtained in a survival analysis because previous studies have reported that survival analyses can be used to determine the correct analytical models to fit herd life data (Ducrocq, 2005; Sewalem et al., 2010; Zavadilová et al., 2011). Additionally, the correlation coefficient between the true breeding value and EBV in a survival analysis was higher than that of a linear model in a simulation study of herd life (Jamrozik et al., 2008). The Spearman's rank correlation coefficients among the EBV of PSR at 305 DIM of Sire30 and the EBV of RR are shown in Table 3. The rank correlation coefficients of EBV of PSR between $\mathrm{H} 5$ and HD were high (0.97-1.00) for Data1-5. The rank correlation coefficients of EBV of PSR between $\mathrm{H} 0$ and $\mathrm{H} 5$ and between H0 and HD were 0.87-0.95 and 0.86-0.96, respectively. These were weaker than those between H5 and HD. The rank correlation coefficients of EBV between PSR and RR were -0.60 to -0.80 . The PSR and RR exhibited opposite trends; accordingly, the genetic correlation between the PSR and RR was negative. Sasaki et al. (2015) reported that the rank correlation coefficient of EBV between the H5 and RR was -0.90 . The lower rank correlation coefficient than that in the previous study can be explained by the smaller data set and the lower heritabilities in this study than in the previous study. Jamrozik et al. (2008) reported that the absolute values of correlation coefficients of EBV of sires with at least 20 daughters for the comparison between a random regression model and PHM ranged from 0.57 to 0.81 . These results were similar to those of this study. The rank correlation coefficients of EBV between PSR and RR increased in the following order: HD, H5, and H0. Additionally, the rank correlation coefficients of the EBV of RR were higher in $\mathrm{H} 5$ and HD than H0; accordingly, the EBV of PSR in H5 and HD were more suitable than those in H0. However, the differences in the heritability estimates and the RV between $\mathrm{H} 0$ and $\mathrm{H} 5$ or $\mathrm{HD}$ were small. The rank correlation coefficients of the EBV of PSR between $\mathrm{H} 0$ and H5 or HD were greater than 0.9.

The reliabilities of the PSR of Sire30 were 0.26 to 0.45 in $\mathrm{H} 0,0.20$ to 0.43 in $\mathrm{H} 5$, and 0.17 to 0.43 in $\mathrm{HD}$ when the effects of other correlated traits were ignored (Figure $5 \mathrm{a}, 5 \mathrm{~b}$, and $5 \mathrm{c})$. The maximum value was obtained at 329 DIM in H0 and 320 DIM in H5 and HD. When the correlations of the PSR with the milk yield and SCS were considered, the reliability of PSR was 0.36 to 0.76 in $\mathrm{H} 0,0.33$ to 0.76 in $\mathrm{H} 5$, and 0.31 to 0.76 in $\mathrm{HD}$.

Table 3. Spearman's correlation coefficients for comparisons among EBV of the pseudo-survival rate for each residual variance type $(\mathrm{H} 0=1$ residual variance for the whole lactation stage; $\mathrm{H} 5=$ separate residual variances for 5 lactation stages; $\mathrm{HD}=1$ residual variance for the whole lactation stage + separate residual variances for 5 lactation stages) at 305 DIM, and EBV of relative risk (RR) of sires with over 30 recorded daughters (Sire30) for each data set (Data1-5)

\begin{tabular}{|c|c|c|c|c|c|c|c|}
\hline \multirow[b]{2}{*}{ Data set } & \multirow{2}{*}{$\begin{array}{l}\text { No. of } \\
\text { Sire30 }\end{array}$} & \multicolumn{3}{|c|}{$\mathrm{H} 0^{1}$} & \multicolumn{2}{|c|}{$\mathrm{H} 5^{1}$} & \multirow{2}{*}{$\frac{\mathrm{HD}^{1}}{\mathrm{RR}^{2}}$} \\
\hline & & $\mathrm{H} 5^{2}$ & $\mathrm{HD}^{2}$ & $\mathrm{RR}^{2}$ & $\mathrm{HD}^{2}$ & $\mathrm{RR}^{2}$ & \\
\hline Data1 & 178 & 0.912 & 0.908 & -0.634 & 0.996 & -0.686 & -0.693 \\
\hline Data2 & 192 & 0.950 & 0.957 & -0.601 & 0.987 & -0.646 & -0.650 \\
\hline Data3 & 181 & 0.940 & 0.952 & -0.721 & 0.990 & -0.685 & -0.716 \\
\hline Data4 & 184 & 0.865 & 0.859 & -0.637 & 0.966 & -0.675 & -0.688 \\
\hline Data5 & 196 & 0.921 & 0.928 & -0.687 & 0.993 & -0.791 & -0.798 \\
\hline Average & 186 & 0.918 & 0.915 & -0.656 & 0.986 & -0.697 & -0.709 \\
\hline
\end{tabular}


These values were 1.3 to 3.5 times higher than those obtained without including the effects of milk yield and SCS in each DIM. The reliability of PSR in H5 and HD was slightly higher than that in $\mathrm{H} 0$ in the late lactation stage (Figure 5b). When the milk yield and SCS were considered, the increment of the reliability of PSR in $\mathrm{H} 5$ and $\mathrm{HD}$ was similar to that in $\mathrm{H} 0$. Because the size of Data1 is one-tenth the size of the original data set, the reliability of PSR of the original data set is higher than that of Data1.

We assumed that the genetic correlation between the PSR and the milk yield in the early lactation stage is negative because high-yielding cows in the early lactation stage have a risk of culling owing to the energy deficit. However, the genetic correlation between

(a) Ho

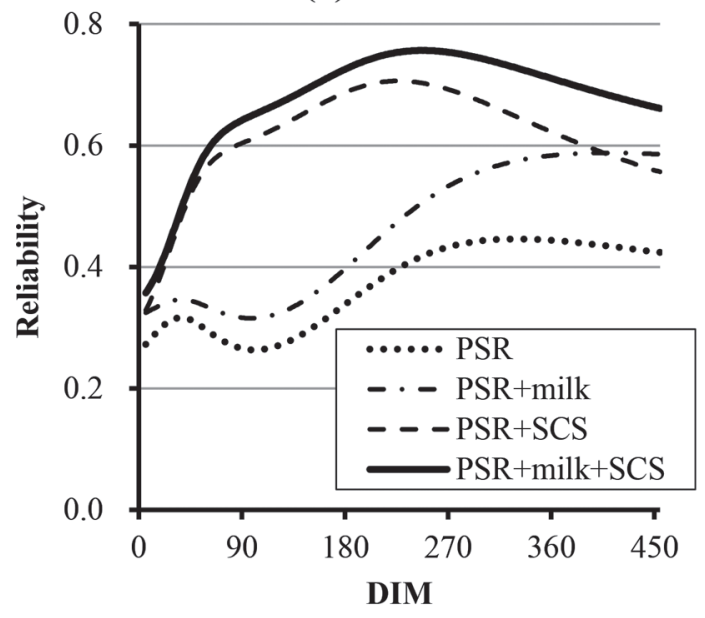

(c) HD

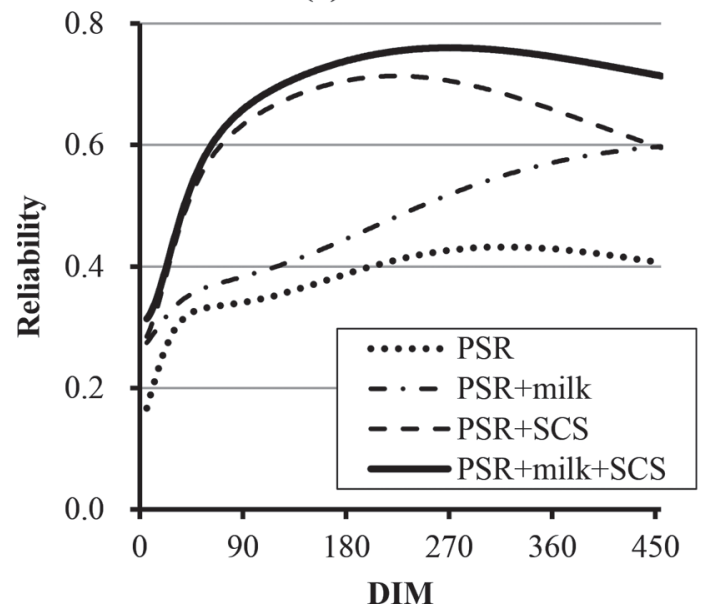

the PSR and the milk yield was positive, but weak in the early lactation stage, and it was strong in the late lactation stage. These results indicate that cows with high production ability remain in their herd, even if they have trouble during the early lactation stage. Cows with low production ability are culled during the dry period. The genetic correlation between the PSR and the SCS was highly negative in all lactation stages. This result indicated that the cows with high SCS had high culling risks at all lactation stages. Because the genetic correlation between the milk yield and the SCS in the early lactation stage was weak, the culling of the high SCS cow in the early lactation stage was not affected by the milk yield. The reliability of the EBV of PSR based on the PSR record was low because 1 (b) $\mathrm{H5}$

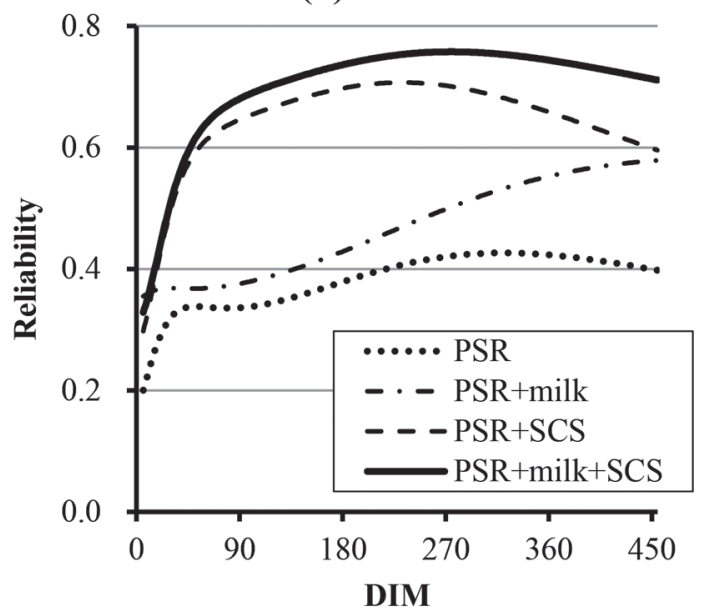

Figure 5. Average reliabilities of the cumulative pseudo-survival rate (PSR) of sires with over 30 recorded daughters, calculated using the multiple-trait random regression animal model. The reliabilities of the EBV of daily PSR were estimated for the following 4 cases: using PSR information (PSR); PSR and milk yield (PSR + milk); PSR and SCS used (PSR + SCS); and PSR, milk yield, and SCS (PSR + milk + SCS). $\mathrm{H} 0=1$ residual variance for the whole lactation stage; $\mathrm{H} 5=$ separate residual variances for the 5 lactation stages; $\mathrm{HD}=1$ residual variance for the whole lactation stage + separate residual variance for the 5 lactation stages. 
PSR record was available for each daughter. When milk yield and SCS, which were genetically correlated with the PSR, were used, the reliability estimate of the EBV of PSR increased. Because the SCS was genetically correlated with the PSR from the early lactation stage, the reliability of EBV of PSR increased from the early lactation stage. Therefore, SCS data were important for improving the reliability of EBV of PSR. The genetic correlation between the milk yield and the PSR in the late lactation stage increased the reliability of EBV of PSR in the late lactation stage. Milk yield information was important because many cows were culled during the late lactation stage. When the breeding value of longevity was estimated, the daughters of young sires remained in the herd, and longevity data were not available. In some longevity studies (Cruickshank et al., 2002; Tsuruta et al., 2005; Hagiya et al., 2012b), the genetic evaluations were based on production traits, SCS, and type traits for accurate estimation.

\section{CONCLUSIONS}

The high genetic correlation in the late lactation stage indicated that the persistency of milk yield is an effective parameter for extending the herd life. Additionally, because the genetic correlation between PSR and SCS is high in all lactation periods, a reduction in the SCS at any time point is effective to extend the herd life. When an elder sire has daughters with longevity records, the reliability of EBV of PSR using milk yield and SCS information is high. Because the reliability of young sires lacking daughters with longevity records is lower, additional information (e.g., production trait data) should be considered.

\section{ACKNOWLEDGMENTS}

We used the supercomputer at the Agriculture, Forestry and Fisheries Research Information Technology Center, Ministry of Agriculture, Forestry and Fisheries, Tokyo, Japan. This work was supported by a grant from the Ministry of Agriculture, Forestry and Fisheries of Japan (Development of Breeding Technology for Animal Life Production).

\section{REFERENCES}

Ali, A. K. A., and G. E. Shook. 1980. An optimum transformation for somatic cell concentration in milk. J. Dairy Sci. 63:487-490.

Bohmanova, J., J. Jamrozik, and F. Miglior. 2009. Effect of pregnancy on production traits of Canadian Holstein cows. J. Dairy Sci. 92:2947-2959.

Carlén, E., U. Emanuelson, and E. Strandberg. 2006. Genetic evaluation of mastitis in dairy cattle using linear models, threshold models, and survival analysis: A simulations study. J. Dairy Sci. 89:4049-4057.
Čejna, V., and G. Chládek. 2005. The importance of monitoring changes in milk fat to milk protein ratio in Holstein cows during lactation. J. Central Eur. Agric. 4:539-546.

Cruickshank, J., K. A. Weigel, M. R. Dentine, and B. W. Kirkpatrick. 2002. Indirect prediction of herd life in Guernsey dairy cattle. J. Dairy Sci. 85:1307-1313.

Ducrocq, V. 2005. An improved model for the French genetic evaluation of dairy bulls on length of productive life of their daughters. J. Dairy Sci. 80:249-256.

Ducrocq, V., J. Sölkner, and G. Mészáros. 2010. Survival Kit v6-A software package for survival analysis. In Proc. 9th World Congress on Genetics Applied to Livestock Production, Communication 02-32. CD ROM, 1-6 August, German Society for Animal Science, Leipzig, Germany.

Fujita, C., and M. Suzuki. 2006. Heritability of herd-life and relationship between herd-life and milk production, type and fertility traits of Holstein cows in Japan. Nihon Chikusan Gakkaiho. 77:9-15.

González-Recio, O., and R. Alenda. 2007. Genetic relationship of discrete-time survival with fertility and production in dairy cattle using bivariate models. Genet. Sel. Evol. 39:391-404.

Hagiya, K., T. Osawa, Y. Masuda, M. Suzuki, T. Yamazaki, Y. Nagamine, and K. Togashi. 2012a. Changes in genetic correlations between herd life and production/type traits over time of Holsteins in Japan. Nihon Chikusan Ggakkaho 83:9-19.

Hagiya, K., T. Osawa, Y. Masuda, M. Suzuki, T. Yamazaki, Y. Nagamine, and K. Togashi. 2012b. Optimal combination of traits to estimate the breeding value of herd life using multiple trait model. Nihon Chikusan Ggakkaho 83:117-123.

Hagiya, K., Y. Terawaki, T. Yamazaki, Y. Nagamine, F. Itho, S. Yamaguchi, H. Abe, Y. Gotoh, T. Kawahara, Y. Masuda, and M. Suzuki. 2013. Relationships between conception rate in Holstein heifers and cows and milk yield at various stages of lactation. Animal 7:1423-1428.

Hagiya, K., T. Yamazaki, Y. Nagamine, K. Togashi, S. Yamaguchi, Y. Gotoh, T. Kawahara, Y. Masuda, and M. Suzuki. 2014. Genetic correlations between production and disease traits during first lactation in Holstein cows. Animal 8:217-223.

Haile-Mariam, M., P. J. Bowman, and M. E. Goddard. 2003. Genetic and environmental relationship among calving interval, survival, persistency of milk yield and somatic cell count in dairy cattle. Livest. Prod. Sci. 80:189-200.

Haile-Mariam, M., and J. E. Pryce. 2015. Variances and correlations of milk production, fertility, longevity, and type traits over time in Australian Holstein cattle. J. Dairy Sci. 98:7364-7379.

Heuer, C., Y. H. Schukken, and P. Dobbelaar. 1999. Postpartum body condition score and results from the first test day milk as predictors of disease, fertility, yield, and culling in commercial herds. J. Dairy Sci. 82:295-304.

Holtsmark, M., B. Heringstad, P. Madsen, and J. Ødegård. 2008. Genetic relationship between culling, milk production, fertility, and health traits in Norwegian Red cows. J. Dairy Sci. 91:4006-4012.

Jamrozik, J., J. Fatehi, and L. R. Schaeffer. 2008. Comparison of model for genetic evaluation of survival traits in dairy cattle: A simulation study. J. Anim. Breed. Genet. 125:75-83.

Liu, Z., F. Reinhardt, A. Bünger, L. Dopp, and R. Reents. 2001. Application of a random regression model to genetic evaluations of test day yields and somatic cell score in dairy cattle. Pages 159-166 in Proc. 2001 Interbull Meeting, Interbull Bulletin No. 27, 30-31 August, Budapest, Hungary.

Liu, Z., F. Reinhardt, A. Bünger, and R. Reents. 2004. Derivation and calculation of approximate reliabilities and daughter yield-deviations of a random regression test-day model for genetic evaluation of dairy cattle. J. Dairy Sci. 87:1896-1907.

Miglior, F., A. Sewalem, J. Jamrozik, J. Bohmanova, D. M. Lefebvre, and R. K. Moore. 2007. Genetic analysis of milk urea nitrogen and lactose and their relationships with other production traits in Canadian Holstein cattle. J. Dairy Sci. 90:2468-2479.

Misztal, I., S. Tsuruta, T. Strabel, B. Auvray, T. Druet, and D. H. Lee. 2002. BLUPF90 and related programs (BGF90). Pages 743-744 in Proc. the 7th World Congress on Genetics Applied to Livestock Production, Vol. 33, 19-23 August, INRA, Montpellier, France. 
Mrode, R., T. Pritchard, M. Coffey, and E. Wall. 2012. Joint estimations of genetic parameters for test-day somatic cell count and mastitis in the United Kingdom. J. Dairy Sci. 95:4618-4628.

Muir, B. L., G. Klstemaker, J. Jamrozik, and F. Canavesi. 2007. Genetic parameters for a multiple-trait multiple-lactation random regression test-day model in Italian Holsteins. J. Dairy Sci. 90:1564-1574.

Onyiro, O. M., L. J. Andrews, and S. Brotherstone. 2008. Genetic parameters for digital dermatitis and correlations with locomotion, production, fertility traits, and longevity in Holstein-Friesian dairy cows. J. Dairy Sci. 91:4037-4046.

Pritchard, T., M. Coffy, R. Mrode, and E. Wall. 2013. Genetic parameters for production, health, fertility and longevity traits in dairy cows. Animal 7:34-46.

SAS Institute Inc. 2006. Base SAS ${ }^{\circledR}$ 9.1.3 Procedures Guide, Second Edition. SAS Institute Inc., Cary, NC.

Sasaki, O., M. Aihara, A. Nishiura, H. Takeda, and M. Satoh. 2015. Genetic analysis of the cumulative pseudo-survival rate during lactation of Holstein cattle in Japan by using random regression models. J. Dairy Sci. 98:5781-5795.

Savegnago, R. P., G. J. M. Rosa, B. D. Valente, L. G. G. Herrera, R. L. R. Carneiro, R. C. Sesana, L. El Faro, and D. P. Munari. 2013 Estimates of genetic parameters and eigenvector indices for milk production of Holstein cows. J. Dairy Sci. 96:7284-7293.

Sewalem, A., F. Miglior, and G. J. Kistemaker. 2010. Analysis of the relationship between workability traits and functional longevity in Canadian dairy breeds. J. Dairy Sci. 93:4359-4365.

Tokuhisa, K., S. Tsuruta, A. De Vries, J. K. Bertrand, and I. Misztal. 2014. Estimation of regional genetic parameters for mortality and 305-d milk yield of US Holsteins in the first 3 parities. J. Dairy Sci. 97:4497-4502.
Toni, F., L. Vincenti, L. Grigoletto, A. Ricci, and Y. H. Schukken 2011. Early lactation ratio of fat and protein percentage in milk is associated with health, milk production, and survival. J. Dairy Sci. 94:1772-1783.

Tsuruta, S., and I. Misztal. 2006. THRGIBBS1F90 for estimation of variance components with threshold and linear models. Pages 27-31 in Proc. the 8th World Congr. Genet. Appl. Livest. Prod., Belo Horizonte, Brazil.

Tsuruta, S., I. Misztal, and T. J. Lawlor. 2004. Genetic correlations among production, boy size, udder, and productive life traits over time in Holstein. J. Dairy Sci. 87:1457-1468.

Tsuruta, S., I. Misztal, and T. J. Lawlor. 2005. Changing definition of productive life in US Holsteins: effect on genetic correlations. J. Dairy Sci. 88:1156-1165.

Varona, L., I. Misztal, and J. K. Bertrand. 1999. Threshold-linear versus linear-linear analysis of birth weight and calving ease using an animal model: I. variance component estimation. J. Anim. Sci 77:1994-2002.

Weller, J. I., and E. Ezra. 2015. Environmental and genetic factors affecting cow survival of Israeli Holstein. J. Dairy Sci. 98:676-684.

Yamazaki, T., K. Hagiya, H. Takeda, O. Sasaki, S. Yamaguchi, M. Sogabe, Y. Saito, S. Nakagawa, K. Togashi, K. Suzuki, and Y. Nagamine. 2013. Genetic correlations between milk production traits and somatic cell scores on test day within and across first and second lactations in Holstein cows. Livest. Sci. 152:120-126.

Zavadilová, L., E. Němcová, and M. Štípková. 2011. Effect of type traits on functional longevity of Czech Holstein cows estimated from a Cox proportional hazard model. J. Dairy Sci. 94:4090-4099. 